\title{
KAJIAN TATA RUANG PASAR TRADISIONAL DI WILAYAH TEMINABUAN KABUPATEN SORONG SELATAN
}

\author{
Agung Pamudjianto ${ }^{1)}$, Roslinda Gomor ${ }^{2)}$, , Faried Desembardi ${ }^{3)}$ \\ 1), 2), 3) Program Studi Teknik Sipil Universitas Muhammadiyah Sorong \\ Jalan Pendidikan No27 Kota Sorong \\ 1) agungumsorong1980@gmail.com
}

\begin{abstract}
Abstrak
Permasalahan yang terjadi di Pasar Sentral Kajase Kabupaten Sorong Selatan saat ini adalah, masih adanya pedagang yang menjajahkan jualannya pada bahu-bahu jalan, parkiran motor (Ojek) yang sembarangan bahkan kadang-kadang memarkirkan motornya didalam pasar yang mengakibatkan tertutupnya los-los ataupun jualan para pedagang dan mengganggu kenyamanan para pembeli, sampah yang berserakah pada ruas jalan yang dapat mengganggu arus lalu lintas, kondisi jalan yang kurang bagus di luar pasar, masih kosongnya sebagian besar los-los dikarenakan masih banyaknya pedagang yang berjualan di Pasar Ampera (Pasar Lama). Pemerintah yang tidak tegas dalam menerapkan peraturan yang sudah di keluarkan dalam hal ini terminal yang sudah ditentukan yaitu pada pasar Kajase (Pasar Baru) tidaklah difungsikan sebagaimana mestinya karena masih ada sebagian taksi yang menggunakan terminal lama pada Pasar Ampera. Taksi-taksi tersebut berasal dari 4 (Empat) Distrik yaitu : Distrik Sawiat, Distrik Seremuk, Distrik Saifi, dan Distrik Fkour. Tujuan penelitian ini adalah mencari alternatif desain tata ruang pasar yang sesuai berdasarkan hasil interview dengan pelaku pasar khususnya Pedagang Papua (Masyarakat Papua). Dari hasil interview tersebut kemudian dilakukan analisa dan dirancang desain pasar tradisional yang sesuai dengan aspirasi masyarakat. Adapun hasil penelitian ini adalah masyarakat adat dan tokoh perempuan sebagai pelaku usaha utama pada pasar tradisional menginginkan desain pasar terbuka, tanpa petak petak toko, tidak bertingkat, dan dari pasar yang sudah ada diharapkan untuk direnovasi dan diminta ada khusus pasar untuk khusus mama mama orang Papua yang berjualan di tempat tersebut, khusus berjualan produk produk lokal dari mama mama Papua sepeti hasil kebun, kerajinan tangan dan souvenir.
\end{abstract}

Kata Kunci : pasar tradisional, sorong selatan, pasar mama mama papua 


\section{PENDAHULUAN}

\subsection{Latar Belakang}

Sejak zaman dahulu kala di wilayah Papua sudah ada pasar rakyat atau pasar tradisional, tetapi tidak menggunakan uang melainkan menggunakan barang atau sistem barter yang dalam bahasa Teminabuan yaitu Frihene. Pasar tradisional ini tidak dilaksanakan setiap hari, tetapi dilakasanakan pada hari-hari tertentu dan tempat pelaksanaannya di tentukan tidak tetap di suatu tempat, desa/kampung. Setelah adanya Pemerintahan secara perlahan-lahan masyarakat mengenal uang dan transaksi di pasar juga berubah dari sistem barter atau pertukaran barang dengan barang menjadi pertukaran uang dengan barang.

Sekarang pasar tradisional telah berubah dan menjadi pusat ekonomi yang sangat penting. Pasar merupakan tempat terjadinya transaksi jual beli antar penjual dan pembeli atau produsen dan konsumen, baik itu pasar tradisional maupun pasar modern. Perkembangan perekonomian di Teminabuan Kabupaten Sorong Selatan pada saat ini bisa diukur dari maraknya pembangunan pusat perbelanjaan. Dapat dilihat banyaknya pembangunan ruko-ruko disepanjang jalan dan juga banyak terdapat pasar-pasar rakyat (Pasar Tradisional), bahkan ada beberapa yang menggunakan Terminal/Halte sebagai tempat berjualan (Pasar Informal).

Tata ruang suatu pasar baik itu pasar modern ataupun pasar tradisional, haruslah di tata dengan sebaik - baiknya agar para pelaku pasar dalam hal ini penjual dan pembeli merasa nyaman dalam melakukan transaksi jual - beli. Seiring dengan berkembangannya zaman, sehingga sangat berpengaruh besar terhadap perkembangan pasar tradisional saat ini khususnya pada tata ruang pasar itu sendiri. Pasar Ampera (Pasar Lama) selama ini menggunakan jalan sebagai tempat berjualan, untuk itu Pemerintah telah membangun pasar baru yaitu Pasar Sentral Kajase. Tetapi masih saja ada pedagang yang bertahan di pasar lama, sehingga pasar yang telah dibangun oleh pemerintah menjadi sepi.

Meskipun bertujuan meningkatkan kinerja dan kualitas pasar, pada kenyataannya program revitalisasi pasar tradisional tidak sepenuhnya menunjukkan keberhasilan. Penelitian yang dilakukan oleh Sitompul, menyatakan sebagian besar pasar yang terbangun dari program revitalisasi belum sepenuhnya berfungsi optimal. Perancangan fisik bangunan menjadi salah satu penyebab pasar tradisional yang terbangun akhirnya sepi (Sitompul, 2012: 143-144).

Skripsi ini membahas tentang permasalah yang muncul pada Pasar Tradisional yang sudah direvitalisasi maupun yang sudah dibangun baru oleh Pemerintah tetapi masih tetap sepi. Seperti yang terjadi pada pasar Sentral Kajase Kabupaten Sorong Selatan, meskipun sudah dibangun tetapi masih sepi akan penjual dan pembeli sehingga banyak pedagang yang mengeluh menderita kerugian.

Permasalahan yang terjadi di Pasar Sentral Kajase Kabupaten Sorong Selatan saat ini adalah, masih adanya pedagang yang menjajahkan jualannya pada bahu-bahu jalan, parkiran motor (Ojek) yang sembarangan bahkan kadang-kadang memarkirkan motornya didalam pasar yang mengakibatkan tertutupnya los-los ataupun jualan para pedagang dan mengganggu kenyamanan para pembeli, sampah yang berserakah pada ruas jalan yang dapat mengganggu arus lalu lintas, kondisi jalan yang kurang bagus di luar pasar, masih kosongnya sebagian besar los-los dikarenakan masih banyaknya pedagang yang berjualan di Pasar Ampera (Pasar Lama). Pemerintah yang tidak tegas dalam menerapkan peraturan yang sudah di keluarkan dalam hal ini terminal yang sudah ditentukan yaitu pada pasar Kajase (Pasar Baru) tidaklah difungsikan sebagaimana mestinya karena masih ada sebagian taksi yang menggunakan terminal lama pada Pasar Ampera. Taksi-taksi tersebut berasal dari 4 (Empat) Distrik yaitu : Distrik Sawiat, Distrik Seremuk, Distrik Saifi, dan Distrik Fkour.

Dalam penyusunan arahan penataan pasar tradisional perlu dilakukan pertimbangan pemenuhan standar penataan fisiknya. Untuk menentukan penataan seperti apa yang perlu diterapkan, diperlukan kriteriakriteria yang dapat digunakan untuk menilai kondisi pasar tradisional yang ada. Dari latar belakang di atas maka penulis tertarik dengan mengambil judul "Kajian Tata Ruang Pasar Tradisional Di Wilayah Teminabuan Kabupaten Sorong Selatan" 


\subsection{Rumusan Masalah}

Kondisi Pasar Ampera (Pasar Lama) sangatlah tidak layak, dikarenakan hampir sebagian besar para pedagang khususnya mama-mama Papua menjajahkan dagangannya pada bahu-bahu jalan bahkan di depan toko pedagang lain. Walaupun sekarang Pemerintah telah membangun pasar baru (Pasar Sentral Kajase), tetapi masih saja ada pedagang yang bertahan di pasar lama. Dan bahkan pasar Sentral Kajase (Pasar Baru) sudah sangat memadai tetapi masih saja ada mama-mama Papua yang berjualan di bahubahu jalan dan kios-kios pedagang lain, walaupun sudah disediakan los-los/blok-blok khusus mama-mama Papua. Oleh sebab itu untuk mencari tahu alasan mengapa mamamama Papua masih bertahan di pasar ampera (pasar lama), dan masih saja ada mamamama Papua yang berjualan di jalan dan didepan kios - kios pedagang lain yaitu dengan turun langsung melakukan interview dengan pedagang - pedagang khusunya Masyarakat Papua.

Berdasarkan latar belakang permasalahaan di atas maka rumusan masalah yang akan di studikan yaitu "Bagaimana desain tata ruang pasar yang baik, berdasarkan hasil interview dengan pelaku pasar khususnya Pedagang Papua (Masyarakat Papua)"

\subsection{Tujuan Penelitian}

Tujuan penelitian ini adalah :

1. Mencari alternatif desain tata ruang pasar yang sesuai berdasarkan hasil interview dengan pelaku pasar khususnya Pedagang Papua (Masyarakat Papua).

\subsection{Batasan Masalah}

Adapun batasan masalah antara lain :

1. Kajian ini fokus hanya mengarah pada unsur tata ruang. Tidak secara mendalam meneliti dan mengulas terkait dengan aspek sosial, dan ekonomi.

2. Hanya mengarah pada rekomendasi desain pasar tradisional sesuai aspirasi dari pemangku kepentingan dilokasi studi.

3. Tidak menghitung anggaran biaya dan desain pasar yang direkomendasi.

\section{METODOLOGI PENELITIAN}

\subsection{Lokasi dan Waktu Penelitian}

\subsubsection{Lokasi Penelitian}

Lokasi penelitian dilakukan di

Teminabuan Kabupaten Sorong Selatan, Propinsi Papua Barat. Kabupaten Sorong

Selatan memiliki 13 Distrik, diantaranya :

1. Distrik Teminabuan

2. Distrik Seremuk

3. Distrik Saifi

4. Distrik Sawiat

5. Distrik Wayer

6. Distrik Moswaren

7. Distrik Konda

8. Distrik Fkour

9. Distrik Inanwatan

10.Distrik Kokoda

11.Distrik Kais

12.Distrik Metemani

13.Distrik Kokoda Utara

Tetapi sehubungan dengan judul yang diambil yaitu "Kajian Tata Ruang Pasar Tradisional di Wilayah Teminabuan Kabupaten Sorong Selatan" maka objek penelitian adalah beberapa pasar tradisional yang ada di Teminabuan dan yang ada di ke-8 distrik yang ada di Teminabuan.

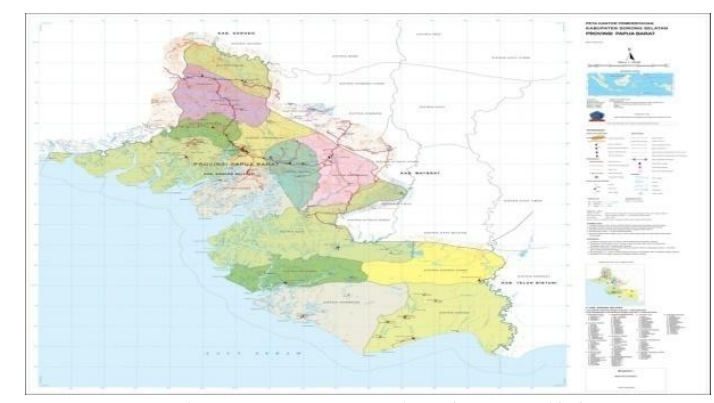

Gambar 1. Peta Lokasi Penelitian

Keterangan :

1. Kuning adalah Distrik Teminabuan

2. Hijau Tua adalah Distrik Seremuk

3. Hijau Muda adalah Distrik Saifi

4. Ungu adalah Distrik Sawiat

5. Biru muda adalah Distrik Wayer

6. Ungu muda adalah Distrik Moswaren

7. Orange muda adalah Distrik Konda

8. Kuning Tua adalah Distrik Fkour

\subsubsection{Waktu Penelitian}

Waktu penelitian adalah selama 2 minggu, yaitu pada bulan Januari 2015. 


\subsection{Tahapan Studi Penelitian}

\subsubsection{Tahapan Persiapan}

Tahapan persiapan adalah tahap dimana penulis memulai persiapan untuk proses pengumpulan dan pengolahan data. Dalam tahap persiapan ini penulis perlu melakukan penelitian secara teliti karena semakin rumit permasalahan yang di hadapi semakin kompleks juga perencanaan yang di lakukan oleh penulis. Agar penulis dapat melakukan perencanaan yang baik sehingga perlu mendapat data - data atau informasi yang lengkap dan akurat yang di sertai dengan konsep. Tahapan-tahapan persiapan ini meliputi :

a. Studi pustaka terhadap materi untuk proses evaluasi

b. Menentukan kebutuhan data

c. Mendata instalasi dan institusi yang dapat dijadikan sumber data

d. Surat-menyurat untuk pengumpulan data.

\subsubsection{Studi Pustaka}

Studi pustaka merupakan salah satu proses dimana penulis mempelajari bukubuku, tulisan ilmiah yang berhubungan dengan penelitian ini sebagai landasan teori dalam penyelesaian pemecahan masalah dan penelitian ini.

\subsection{Teknik Pengumpulan dan Pengolahan Data}

\subsubsection{Teknik Pengumpulan Data}

Teknik pengumpulan data merupakan langkah setelah tahap persiapan dalam proses pelaksanaan evaluasi yang sangat penting, karena dapat ditentukan permasalah dan rangkaian penentuan alternative pemecahan masalah yang akan diambil. Adapun beberapa metode yang dilakukan dalam tahap pengumpulan data ini antara lain :

\section{a. Data primer berupa :}

Data primer adalah data yang diperoleh langsung dari lapangan meliputi :

1. Interview/Wawancara

Wawancara atau Tanya jawab langsung terhadap pedagang-pedagang yang ada di Pasar Ampera (Pasar Lama), Pasar Sentral Kajase Kabupaten Sorong Selatan (Pasar Baru), dan beberapa pasar yang ada di distrik-distrtrik.

2. Kuesioner

Kuesioner yaitu daftar pertanyaan digunakan untuk memperoleh data. Kuesioner ini dilakukan dengan mengajukan lembaran angket kepada responden, yang berisikan daftar pertanyaan yang bersifat tertutup artinya jawaban alternatif telah disediakan.

3. Observasi

Metode observasi yaitu metode pengumpulan data melalui pengamatan secara langsung pada obyek penelitian, yaitu di Pasar Ampera (Pasar Lama), Pasar Sentra Kajase, dan beberapa pasar yang ada di Teminabuan Kabupaten Sorong Selatan.

\section{b). Data sekunder berupa :}

Data sekunder adalah data yang didapatkan secara tidak langsung dari objek yang diteliti. Data ini diperoleh melalui studi pustaka, yaitu dari buku atau literatur yang ada kaitannya dengan masalah yang akan diteliti.

\subsubsection{Pengolahan Data}

Data yang telah dikumpulkan diolah melalui beberapa tahapan sebagai berikut (Nazir, 2003):

\section{Mengedit Data (Editing)}

Editing merupakan proses yang dilakukan sebelum data diolah. Data yang diperoleh diedit untuk memperbaiki kualitas data serta menghilangkan keraguan terhadap data yang diperoleh, serta untuk memastikan konsistensi data tersebut. Editing juga dilakukan untuk memilih data yang akan digunakan dan data yang tidak dapat digunakan atau harus dikonfirmasi ulang.

2. Analisis

Kegiatan terakhir dalam mengolah data adalah analisis data yaitu dengan, mengelompokkan, membuat suatu urutan, memanipulasi serta menyingkatkan data sehingga mudah untuk dibaca. Analisis dilakukan sesuai dengan tujuan penelitian yaitu dengan memperlihatkan sesuatu yang khas atau penunjukan kecenderungan tengahtengah dari variable-variabel yang dianalisis.

Dalam penelitian ini pengolahan dan analisa data dengan menggunakan atau mendeskripsikan hasil wawancara dan Autocad, sedangkan untuk penentuan kuisioner menggunakan Rumus Slovin.

Semua metode penulisan dan analisa dalam artikel ilmiah ini merujuk pada panduan penulisan tugas akhir Fakultas Teknik Universitas Muhammadiyah Sorong tahun 2014 (Pristianto, Amri, \& Rusdi, 2014). 
III. ANALISA DATA DAN PEMBAHASAN

\subsubsection{Kondisi Pasar}

\section{Pasar Ampera (Pasar Lama)}

Sebelum Pasar Kajase dibangun, Pasar Ampera (Pasar Lama) sudah ada sejak Teminabuan terbentuk dan belum menjadi Kabupaten. Kondisi pasar sangatlah tidak layak, dikarenakan hampir sebagian besar para pedagang khususnya mama-mama Papua menjajahkan dagangannya pada bahubahu jalan bahkan di depan toko pedagang lain. Tidak ada sarana prasarana yang baik, bahkan sampah yang ada tepat ditengahtengah pasar dibiarkan berserakah karena tidak ada bak sampah untuk menampung sampah yang ada.

Pihak Pemerintah sudah tidak memperhatikan pasar tersebut, karena Pemerintah telah membangun pasar baru yang dilengkapi dengan segala fasilitas dan Pemerintah berharap mama-mama papua dapat berjualan di pasar baru tersebut. Tetapi yang terjadi masih ada mama-mama papua yang berjualan di pasar lama tersebut dengan berbagai alasan yaitu, masalah tranportasi dan masalah desain pasar baru tersebut.

$>$ Aksesibilitas

Akses transportasi dari kampungkampung lancar, dan akses keluar masuk dapat dengan mudah ditemukan, setiap kios dagang dapat dengan mudah diakses oleh para pembeli, jalan utama mudah ditemukan dan dicapai (karena lokasi pasar yang terletak di tengah pemukiman penduduk, dan juga pasar ini menggunakan jalan sebagai tempat berjualan).

$>$ Sarana dan Prasarana

Hampir tidak ada sarana prasarana yang ada di pasar ampera ini karena pasar ini hanya menggunakan jalan sebagai tempat berjualan, hanya ada tempat sampah yang terletak di tengah-tengah pasar. Tidak ada fasilitas lain seperti : WC/Toilet, Pos jaga, lahan parkir, dan Mushola.

Dan jawaban-jawaban yang diberika hampir semua jawaban mama-mama sama, yaitu :

$>$ Hasil Interview

1. Harus ada penambahan pasar tradisional, yang berlokasi di pasar lama itu sendiri

2. Desain pasarnya terbuka, tidak memakai los-los/kios-kios
(Dibiarkan terbuka agar mama-mama dapat menggelar jualannya), dan tanpa pemilik. Serta dibagi berdasarkan Distrik.

3. Dan kalau bisa Pemerintah dapat membangun pasar tradisional yang di peruntukan khusus mama-mama papua.

\section{Pasar Sentral Kajase (Pasar Baru)}

Pasar Sentral Kajase Kabupaten Sorong Selatan saat ini masih dalam tahap pembangunan, tetapi kondisi yang saya temukan dilapangan sama dengan kondisi yang ada di Pasar Ampera (pasar lama). Yaitu masih adanya mama-mama Papua yang menjajahkan jualannya pada bahu-bahu jalan dan didepan toko pedagang lain walaupun sudah ada los/blok khusus untuk mamamama Papua. Jika ditanya alasannya ialah : Panjang los yang dianggap terlalu panjang, dan mereka tidak berjualan permanen (hanya sementara saja) untuk itu mereka tidak membutuhkan los/blok. Dan bahkan ada yang menambahkan meja jualan mereka dan meletakkannya diatas saluran drainase.

$>$ Aksesibilitas

Akses transportasi dari kampungkampung lancar tetapi ada keluhan menganai biaya transportasi yang mahal, akses keluar masuk dapat dengan mudah ditemukan, setiap kios/los dagang dapat mudah diakses oleh para pembeli, jalan utama mudah ditemukan dan dapat dicapai dengan menggunakan kendaraan beroda 2 (motor) maupun beroda 4 (mobil).

$>$ Sarana dan Prasarana

Sarana dan prasarana yang ada di pasar Sentral Kajase sudah cukup memadai, mulai dari WC/Toilet yang bersih dan terdapat di sudut-sudut pasar, pos penjagaan, terdapat 2 (dua) Mushola, dan terminal yang sangat besar. Tetapi masih ada kekurangan di beberapa sarananya, antara lain : masih kurangnya kebersihan pasar yaitu dengan mudahnya kita dapat menemukan sampah yang yang berserakah di beberapa titik, bahkan ada yang memasuki badan jalan. Kurangnya lahan parkir yang mengakibatkan banyak motor yang memarkirkan kendaraan mereka di dalam pasar, sehingga menghalang dagangan para pedagang dan mengganggu para pembeli, serta ruas jalan masuk menuju pasar rusak. 
Dan jawaban-jawaban yang diberika hampir semua jawaban mama-mama sama, yaitu :

\section{$>$ Hasil Interview}

Desain pasarnya kalau direvitalisasikan, kiranya dibuat berlantai 2, agar mamamama papua di lantai 1 bersama degan pedagang non-papua tetapi yang dagangannya berupa sayur-sayuran dan buah-buahan. Sedangkan pada lantai 2 ditempati oleh pedagang pakaian dan pernak-pernik lainnya. Contohnya : Pasar Hamadi Jayapura, dan Pasar Tambaruni Fak-Fak.

\subsubsection{Analisa Data dengan Pihak Terkait}

Data-data yang telah dikumpulkan dari hasil penelitian yang dilakukan selama 2 minggu yaitu dari pihak Pemerintah (DPR dan DISPERINDAGKOP \& UKM), dan LMA (Lembaga Masyarakat Adat). Pada rencana awal yang akan diwawancara yaitu DPR (Dewan Perwakilan Rakyat), dan Dinas PERINDAGKOP \& UKM. Tetapi setelah dilapangan dari pihak Pemerintah yang bisa ditemui dan diwawancarai adalah dari Dinas PERINDAGKOP \& UKM.

\subsubsection{DISPERINDAGKOP \& UKM}

Wawancara yang saya lakukan dengan

Kepala Dinas PERINDAGKOP dan UKM Kabupaten Sorong Selatan, yaitu Bapak. Nimrod Nauw, SE.MA, adalah sebagai berikut:

Tabel 1. Hasil interview dengan DISPERINDAGKOP \& UKM

\begin{tabular}{|c|c|c|}
\hline No & Pertanyaan & Jawaban \\
\hline 1 & $\begin{array}{l}\text { Berapa jumlah } \\
\text { pasar tradisional di } \\
\text { Kabupaten Sorong } \\
\text { Selatan? }\end{array}$ & 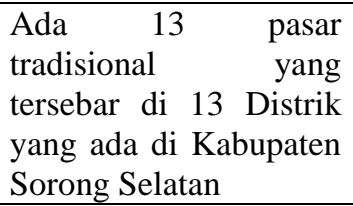 \\
\hline 2 & $\begin{array}{l}\text { Apakah sudah ada, } \\
\text { PERDA untuk } \\
\text { pasar tradisional? }\end{array}$ & $\begin{array}{l}\text { Belum ada (dalam } \\
\text { proses penyusunan), } \\
\text { dan untuk sementara } \\
\text { menggunakan } \\
\text { Bupati }\end{array}$ \\
\hline 3 & $\begin{array}{l}\text { Apakah sudah ada } \\
\text { desain baku pasar } \\
\text { tradisional? }\end{array}$ & $\begin{array}{lll}\text { Ada. (Desain } & \text { Pasar } \\
\text { Sentral Kajase) } & \end{array}$ \\
\hline 4 & $\begin{array}{lr}\text { Desain pasar yang } \\
\text { di } \quad \text { lapangan, } \\
\text { apakah diambil } \\
\text { dari desain } & \text { pasar } \\
\text { Provinsi } & \text { atau } \\
\text { Kabupaten? } & \\
\end{array}$ & $\begin{array}{lr}\text { Desain } & \text { pasar } \\
\text { tradisional } & \text { yang } \\
\text { diterapkan di lapangan } \\
\text { yaitu dari desain pasar } \\
\text { Kabupaten }\end{array}$ \\
\hline 5 & $\begin{array}{lr}\text { Apakah } & \text { ada } \\
\text { rencana } & \text { kedepan }\end{array}$ & $\begin{array}{l}\text { Iya, dikawasan baru } \\
\text { Mlasolo/Perbatasan }\end{array}$ \\
\hline
\end{tabular}

\begin{tabular}{|c|c|c|}
\hline & $\begin{array}{l}\text { untuk membangun } \\
\text { pasar tradisional di } \\
\text { lokasi lain? }\end{array}$ & $\begin{array}{lr}\text { Kabupaten } & \text { Sorong dan } \\
\text { Kabupaten } & \text { Sorong } \\
\text { Selatan } & \\
\end{array}$ \\
\hline 6 & $\begin{array}{l}\text { Apakah ada } \\
\text { keluhan tentang } \\
\text { pasar tradisional } \\
\text { yang sudah ada? } \\
\text { Dari segi lokasi, } \\
\text { kebersihan, } \\
\text { transportasi, dan } \\
\text { prasaran lainnya? }\end{array}$ & $\begin{array}{lr}\text { Ada, } & \text { khususnya } \\
\text { kebersihan } & \text { dan } \\
\text { transportasi } & \end{array}$ \\
\hline 7 & $\begin{array}{l}\text { Tindakan apa yang } \\
\text { dilakukan } \\
\text { Pemerintah dalam } \\
\text { menangani } \\
\text { keluhan-keluhan } \\
\text { tersebut? }\end{array}$ & 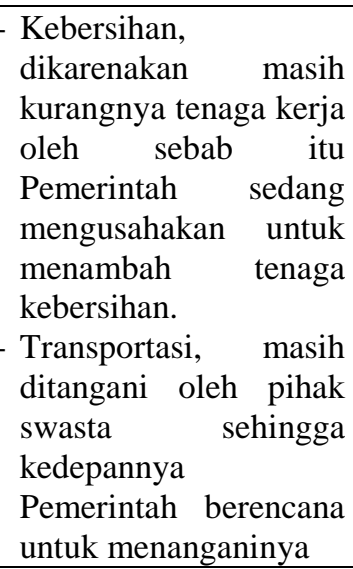 \\
\hline
\end{tabular}

\subsubsection{Pihak LMA}

Dari 8 Distrik yang ada di Teminabuan yang dapat diwawancarai yaitu LMA dari Suku Tehit yang berada di Distrik Teminabuan, dan yang mewakili dari Tokoh Perempuan yaitu Ibu Sarce Saflesa, interview yang dilakukan adalah sebagai berikut :

Tabel 2. Hasil interview dengan LMA/Tokoh Perempuan

\begin{tabular}{|c|c|c|}
\hline No & Pertanyaan & Jawaban \\
\hline 1 & $\begin{array}{l}\text { Apakah desain } \\
\text { pasar yang sudah } \\
\text { ada, sudah sesuai } \\
\text { dengan keinginan } \\
\text { pelaku pasar, } \\
\text { khususnya mama- } \\
\text { mama papua? }\end{array}$ & $\begin{array}{lr}\text { Tidak bisa } & \text { bilang } \\
\text { belum sesuai, } & \text { karena } \\
\text { Pemerintah } & \text { sudah } \\
\text { punya niat baik } & \text { untuk } \\
\text { membangun } & \text { pasar. } \\
\text { Hanya saja mungkin } & \text { ran } \\
\text { saran } & \text { untuk } \\
\text { Pemerintah, } & \\
\text { kedepannya kalau mau } \\
\text { membangun sebuah } \\
\text { pasar tradisional harus } \\
\text { melibatkan pelaku } \\
\text { pasar } \\
\text { mama-mama khususnya } \\
\begin{array}{lr}\text { dan tua-tua } \\
\text { dengan terlebih dahulu } \\
\text { melakukan suatu kajian }\end{array}\end{array}$ \\
\hline 2 & $\begin{array}{l}\text { Apakah ibu akan } \\
\text { setuju jika pasar di } \\
\text { desain } 1 \text { lantai, } 2 \\
\text { lantai, atau lebih? } \\
\text { Alasanya? }\end{array}$ & $\begin{array}{l}\text { Tidak perlu dibangun } \\
\text { berlantai } 2 \text { atau lebih, } \\
\text { cukup dibangun } \\
\text { sederhana saja. Dan } \\
\text { kalau bisa Pemerintah } \\
\text { disarankan membangun }\end{array}$ \\
\hline
\end{tabular}




\begin{tabular}{|c|c|c|}
\hline & & $\begin{array}{lr}\text { pasar tradisional yang } \\
\text { dikhususkan untuk } \\
\text { mama-mama Papua, } \\
\text { serta pasar tradisional } \\
\text { tersebut } \\
\text { mengangkat kearifan } \\
\text { budaya lokal setempat } \\
\text { (Tehit) }\end{array}$ \\
\hline 3 & $\begin{array}{l}\text { Apakah ada } \\
\text { keluhan tentang } \\
\text { pasar tradisional } \\
\text { yang sudah ada? } \\
\text { Dari segi lokasi, } \\
\text { kebersihan, } \\
\text { transportasi, dan } \\
\text { prasaran lainnya! }\end{array}$ & $\begin{array}{l}\text { Ada banyak keluhan, } \\
\text { tetapi lebih khususnya } \\
\text { dari segi lokasi dan } \\
\text { desain pasar tradisional }\end{array}$ \\
\hline 4 & $\begin{array}{l}\text { Tindakan apa yang } \\
\text { dilakukan } \\
\text { Pemerintah dalam } \\
\text { menangani } \\
\text { keluhan-keluhan } \\
\text { tersebut? }\end{array}$ & $\begin{array}{l}\text { Tindakan yang diambil } \\
\text { LMA adalah semua } \\
\text { keluhan-keluhan } \\
\text { tersebut sudah } \\
\text { dilanjutkan ke pihak } \\
\text { Pemerintah, dan sudah } \\
\text { ditindaklanjuti dengan } \\
\text { membangun pasar baru } \\
\text { (Pasar Sentral Kajase). } \\
\text { Hanya saja } \\
\text { permasalahannya, } \\
\text { lokasi dan desain pasar } \\
\text { tidak sesusai dengan } \\
\text { keinginan mama- } \\
\text { mama papua }\end{array}$ \\
\hline
\end{tabular}

\subsection{Pembahasan}

Permasalahan yang terjadi di pasar-pasar yang ada di Teminabuan Kabupaten Sorong Selatan hampir sama dengan permasalahan pasar yang ada di Papua, yaitu walaupun Pemerintah telah membangun pasar tetapi masih saja ada mama-mama papua yang berjualan di pinggir jalan. Serta pasar-pasar yang telah dibangun oleh Pemerintah pada tiap-tiap distrik, terbengkalai begitu saja dan tidak dipakai.

Orang Papua, terbiasa menjual barang dagangannya dengan menggelar seadanya ditanah. Menurut mereka, hasil bumi harus dijual dibumi pula. Banyak kita temui warga asli papua berjualan di pinggir jalan, hanya bermodalkan terpal untuk menaruh dagangan mereka. Wajar apabila kita jarang menemui penduduk asli papua berjualan dikios. (M Syarif, 2010).

Tujuan penelitian ini adalah : Mencari alternatif desain tata ruang pasar yang sesuai berdasarkan hasil interview dengan pelaku pasar khususnya Masyarakat Papua (mamamama papua).
Dari hasil interview/wawancara saya dengan mama-mama papua, baik yang ada di Pasar Ampera (Pasar Lama), maupun Pasar Sentral Kajase (Pasar Baru), keinginan ataupun tanggapan mereka berbeda. Muncul beberapa alternatif yaitu :

1. Desain pasarnya terbuka, tidak memakai los-los/kios-kios (Dibiarkan terbuka agar mama-mama dapat menggelar jualannya), dan tanpa pemilik. Serta dibagi berdasarkan Distrik. Dan kalau bisa Pemerintah dapat membangun pasar tradisional yang di peruntukan khusus mama-mama papua.

2. Desain pasarnya kalau diubah atau direvitalisasikan, kiranya dibuat berlantai 2 (dua), agar mama-mama papua di lantai 1 (satu) bersama degan pedagang non-papua tetapi yang dagangannya berupa sayur-sayuran dan buah-buahan. Sedangkan pada lantai 2 (dua) ditempati oleh pedagang pakaian dan pernakpernik lainnya. Contohnya : Pasar Hamadi Jayapura, dan Pasar Tambaruni Fak - Fak.

\section{KESIMPULAN}

Berdasarkan hasil penelitian di Kabupaten Sorong Selatan tentang tata ruang pasar tradisional maka didapat kesimpulan, yaitu: bahwa pasar Ampera diharapkan adanya pembangunan pasar baru yang berlokasi di pasar lama itu sendiri, dan desain pasarnya terbuka, tidak memakai los/kios (Dibiarkan terbuka agar mama-mama dapat menggelar jualannya), dan tanpa pemilik. Serta dibagi berdasarkan Distrik. Dan kalau bisa Pemerintah dapat membangun pasar tradisional yang di peruntukan khusus mama-mama papua. Pasar Sentral Kajase diharapkan adanya revitalisasi dan kiranya dibuat berlantai 2, agar mama-mama papua di lantai 1 bersama degan pedagang nonpapua tetapi yang dagangannya berupa sayur-sayuran dan buah-buahan. Sedangkan pada lantai 2 ditempati oleh pedagang pakaian dan pernak-pernik, dan lain-lain. (Contohnya : Pasar Hamadi Jayapura, dan Pasar Tambaruni Fak-Fak). Jika tidak direvitalisasi, kiranya dirubah penempatan los-losnya saja yaitu dengan meletakan 
pedagang Papua didepan tidak seperti sekarang yang posisinya di tengah. LMA/Tokoh Perempuan (Suku Tehit) merekomendasikan Pasar cukup dibangun sederhana saja, tidak perlu dibuat bertingkat yang penting mama-mama Papua terlindungi dari hujan dan panas matahari, dan kalau bisa Pemerintah dapat membangun pasar tradisional yang dikhususkan untuk mamamama papua, serta pasar tradisional tersebut harus mengangkat kearifan budaya lokal setempat (Tehit).

\section{Daftar Pustaka}

Agus S.Ekomadyo, Sultan Hidayat, 2012 Isu, Tujuan, Dan Kriteria Perancangan Pasar Tradisional

Dwi Ananta Devy, 2005 Kajian Terhadap Pemanfaatan Ruang Di Pasar Tradisional Bulu Semarang, Semarang

Dyah Arum Istiningtyas, 2008 Analisis Kebijakan Dan Strategi Pengembangan Pasar Tradisional Di Kota Bogor

Keputusan Menteri Pekerjaan Umum No.378/Kpts/1987 Tentang Pengesahan 33 Standar Konstruksi Bangunan Indonesia

Mudrajad Kuncoro (2008), Isu Utama Yang Berkaitan Dengan Perkembangan Pasar Tradisional

Pristianto, H., Amri, I., \& Rusdi, A. (2014, May 9). Pedoman Penulisan Tugas Akhir Fakultas Teknik Universitas Muhammadiyah Sorong 2014. http://doi.org/10.17605/OSF.IO/4VTJ M.

Ucang Sukriswanto, 2012 Analisis Kelayakan Revitalisasi Pasar Umum Gubug Kabupaten Grobogan 